
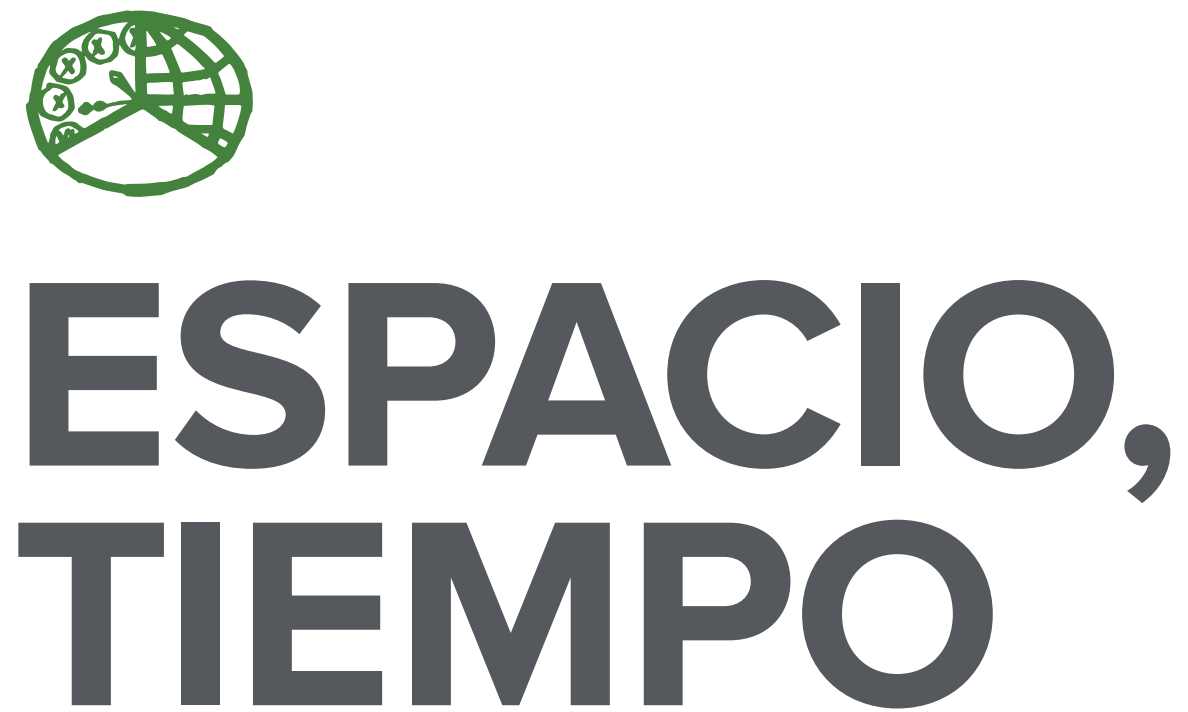

AÑO 2020

ISSN 1130-2968

E-ISSN 2340-146X
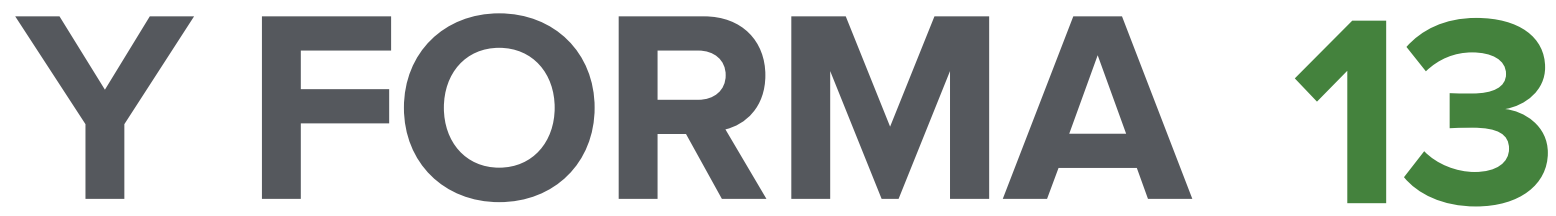

SERIE VI GEOGRAFÍA

REVISTA DE LA FACULTAD DE GEOGRAFÍA E HISTORIA 


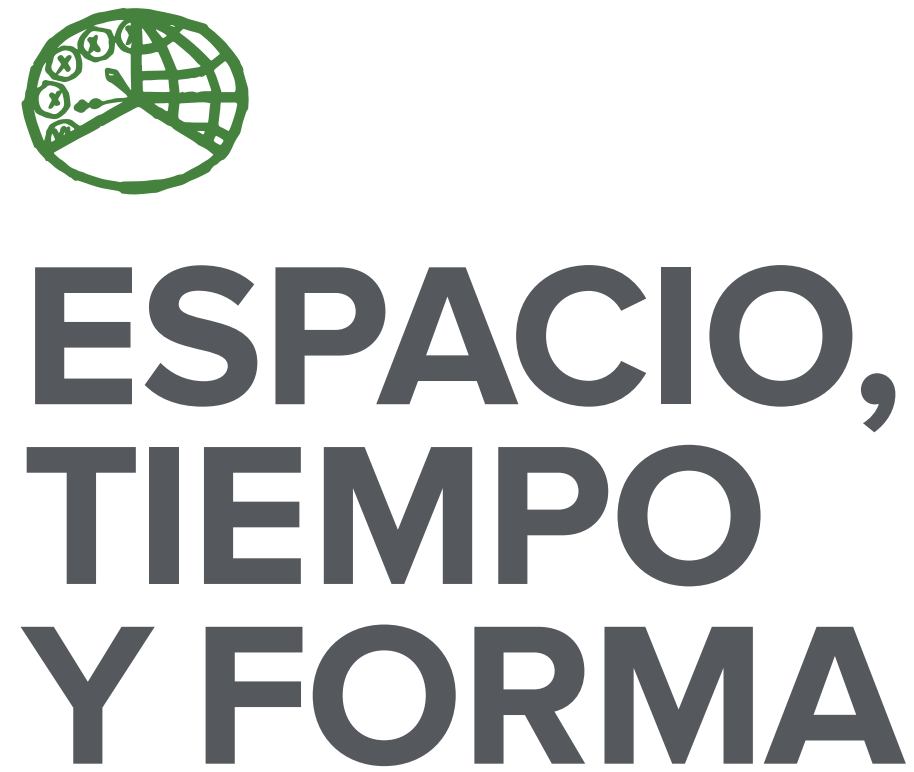

AÑO 2020

ISSN 1130-2968

E-ISSN 2340-146X

SERIE VI GEOGRAFÍA

REVISTA DE LA FACULTAD DE GEOGRAFÍA E HISTORIA

DOI: http://dx.doi.org/10.5944/etfvi.13.2020

\section{UחED}

UNIVERSIDAD NACIONAL DE EDUCACIÓN A DISTANCIA 
La revista Espacio, Tiempo y Forma (siglas recomendadas: ETF), de la Facultad de Geografía e Historia de la UNED, que inició su publicación el año 1988, está organizada de la siguiente forma:

$$
\begin{aligned}
& \text { SERIE I - Prehistoria y Arqueología } \\
& \text { SERIE II - Historia Antigua } \\
& \text { SERIE III - Historia Medieval } \\
& \text { SERIE IV - Historia Moderna } \\
& \text { SERIE V - Historia Contemporánea } \\
& \text { SERIE VI - Geografía } \\
& \text { SERIE VII - Historia del Arte }
\end{aligned}
$$

Excepcionalmente, algunos volúmenes del año 1988 atienden a la siguiente numeración:

$$
\begin{aligned}
& \mathrm{N}^{\circ} 1 \text { - Historia Contemporánea } \\
& \mathrm{N}^{\circ} 2 \text { - Historia del Arte } \\
& \text { N. }{ }^{\circ} 3 \text { - Geografía } \\
& \mathrm{N} .^{\circ} 4 \text { - Historia Moderna }
\end{aligned}
$$

ETF no se solidariza necesariamente con las opiniones expresadas por los autores.

\author{
UNIVERSIDAD NACIONAL DE EDUCACIÓN A DISTANCIA \\ Madrid, 2020 \\ SERIE VI $\cdot$ GEOGRAFÍA N. ${ }^{\circ} 13,2020$ \\ ISSN $1130-2968 \cdot$ E-ISSN 2340-146x \\ DEPÓSITO LEGAL \\ $M-21.037-1988$ \\ URL \\ ETF VI - GEOGRAFÍA $\cdot h t t p: / / r e v i s t a s . u n e d . e s / i n d e x . p h p / E T F V I$ \\ DISEÑO Y COMPOSICIÓN \\ Carmen Chincoa Gallardo · http://www.laurisilva.net/cch \\ Impreso en España · Printed in Spain
}




\section{ARTÍCULOS · ARTICLES}





\title{
A PROPOSTA DO CAMINHO PARA OS ERVAIS: DESENVOLVENDO TERRITÓRIOS ATRAVÉS DA CRIAÇÃO DE ITINERÁRIOS CULTURAIS NA FRONTEIRA BRASIL-PARAGUAI
}

\section{THE PROPOSAL OF «CAMINHO PARA OS \\ ERVAIS»: DEVELOPING TERRITORIES THROUGH CREATION OF CULTURAL ITINERARIES IN BRAZIL-PARAGUAY BORDER}

\author{
Carlos B. Buson; Carlos O. Zamberlan²; Cláudia M. Sonaglio³ \& Fabrício J. Missio4 \\ Recibido: 03/04/2020 - Aceptado: 10/07/2020 \\ DOI: http://dx.doi.org/10.5944/etfvi.13.2020.27170
}

\begin{abstract}
Resumo 5
Os itinerários culturais são tidos como alternativas para fomentar o desenvolvimento de uma região, considerando principalmente o resgate cultural que pode ser proporcionado por eles. A cultura é, também, vista como um bem que pode ser utilizado no saneamento de problemas socioeconômicos dos territórios no momento que ativa ou reativa sistemas sociais e econômicos como a educação, o turismo, a produção artesanal, entre outros. Assim, este estudo apresenta uma proposta de itinerário cultural para a franja da fronteira oeste sul-mato-grossense e que é caracterizada por uma série de indicadores socioeconômicos que demonstram sua fragilidade. A proposta desse trabalho nasce de um projeto de pesquisa da identidade cultural da fronteira do mestrado de Desenvolvimento Regional e Sistemas Produtivos (PPGDRS) da Universidade Estadual de Mato Grosso do Sul (UEMS) com vistas a desenvolver mecanismos de desenvolvimento aptos para o território. Depois de uma etapa de identificação da realidade local se efetuou uma revisão bibliográfica e cartográfica da região para conhecer sua história desde o
\end{abstract}

1. Universidade Estadual de Mato Grosso do Sul. Mestrado em Desenvolvimento Regional e de Sistemas Produtivos; <cbuson@gmail.com>.

2. Universidade Estadual de Mato Grosso do Sul. Mestrado em Desenvolvimento Regional e de Sistemas Produtivos; <otaviozamberlan@gmail.com>.

3. Universidade Estadual de Mato Grosso do Sul. Mestrado em Desenvolvimento Regional e de Sistemas Produtivos; <claudia.sonaglio@gmail.com>.

4. Universidade Estadual de Mato Grosso do Sul (Universidade Federal de Minas Gerais). Mestrado em Desenvolvimento Regional e de Sistemas Produtivos e CEDEPLAR - UFMG; <fabriciomissio@gmail.com>.

5. «O presente trabalho foi realizado com apoio da Coordenação de Aperfeiçoamento de Pessoal de Nível Superior - Brasil (CAPES) - Código de Financiamento ool «This study was financed in part by the Coordenação de Aperfeiçoamento de Pessoal de Nível Superior - Brasil (CAPES) - Finance Code ooı». 
período colonial. Nesta fase podem-se encontrar diversos materiais, documentos, mapas que asseguram a presença de um antigo caminho que cruzava o território de norte a sul. A região desse itinerário é marcada fortemente pela cultura da erva mate, pela interação entre etnias e múltiplas culturas. O trajeto apresentado se mostra presente nos documentos históricos como importante via de acesso ao longo do processo de formação histórico econômica da região. Atualmente, o que se observa na área de abrangência deste itinerário é uma heterogeneidade econômica com predominância de baixo desenvolvimento e pobreza.

Palavras-chave

Cultura; Pobreza; Desenvolvimento Territorial; Patrimônio.

\section{Abstratc}

Cultural itineraries are considered as alternatives to foster the development of a region, especially considering the cultural rescue that can be provided by them. Culture is also seen as a good that can be used to remedy the socioeconomic problems of the territories when activating or reacting social and economic systems such as education, tourism, artisanal production, among others. Thus, this study presents a cultural itinerary proposal for the fringe of the western border of Mato Grosso and which is characterized by a series of socioeconomic indicators that demonstrate its fragility. The purpose of this work is born from a research project of cultural identity of the frontier of the Master of Regional Development and Productive Systems (PPGDRS) of the State University of Mato Grosso do Sul (UEMS) in order to develop development mechanisms suitable for the territory. After a step of identifying the local reality, a bibliographic and cartographic revision of the region was carried out to know its history since the colonial period. In this phase you can find various materials, documents, maps that ensure the presence of an ancient path that crossed the territory from north to south. The region of this itinerary is strongly marked by the culture of yerba mate, the interaction between ethnicities and multiple cultures. The path presented is shown in the historical documents as an important way of access throughout the process of historical economic formation of the region. Currently, what is observed in the area covered by this itinerary is an economic heterogeneity with a predominance of low development and poverty.

Keywords

Culture; Poverty; Territorial Development; Patrimony. 


\section{INTRODUÇÃO}

Os itinerários culturais têm ganhado destaque na atualidade, pois possibilitam uma geração de dinâmicas nos territórios promotoras da implementação de valor de bens patrimoniais, da identificação cultural e do desenvolvimento com sustentabilidade por meio da promoção e comercialização de recursos endógenos. Considerando o exposto no $2^{\circ}$ relatório mundial da UNESCO (2009) sobre diversidade cultural, o desenvolvimento em uma perspectiva cultural na visão do mundo industrializado está dentro de uma relação causal entre cultura e subdesenvolvimento. O que isso significa? Significa pertencer a um mundo de valores ocidentais e, por meio disso, ter resultados econômicos positivos. Essa concepção de desenvolvimento é atualmente questionada dentro de uma construção mais ampla sobre o tema, onde se busca considerar os fatores sociais e culturais. Também entram nesse construto a participação da comunidade nos processos de preparação e execução dos projetos econômicos inferindo a todos uma parcela dos resultados, e, com isso, uma melhor distribuição de renda e maior qualidade de vida.

Frente a essa concepção de desenvolvimento, mais abrangente, que envolve elementos culturais e participativos, é que se torna importante o conceito de Itinerário Cultural como um fator que decorre do intercâmbio de culturas e da formação de diversidade, onde sua concretização é decorrente de um projeto de participação comunitária e usufruto também participativo de parcela dos resultados sociais e econômicos provenientes desse projeto. O Itinerário cultural, diante dessa perspectiva, torna-se um patrimônio da comunidade que cria identidade e engajamento da população com o território.

O engajamento das populações locais se dá pela representação dos itinerários às trajetórias de formação social e econômica, pelo resgate histórico dos processos de evolução, pelo aflorar de crenças, ritos e personagens que exerceram papel importante na formação do território, ou de uma localidade específica, que passa a criar uma identificação social e um valor, um sentimento de honra e pertencimento. Os itinerários culturais, frente ao exposto, são produtos culturais territoriais originados por processos históricos de trocas que tem potencialidade de ser usado como produtos turísticos, e, portanto, gerando um impacto na economia regional. Ademais, a identificação territorial tem potencial de ser extrapolada para fora da região por meio de marcas de produtos com destino a exportação (exportação para fora da região, não necessariamente para outro país) que carreguem símbolos regionais que dêem valor agregado e beneficiem algum sistema produtivo local. Mas qual a definição de um Itinerário Cultural? Um itinerário cultural $^{6}$ é definido como uma via de comunicação, que pode ser terrestre, aquática ou mista, que seja fisicamente determinada, com dinâmicas e funcionalidades históricas próprias, que se manifesta em trocas contínuas, multidimensionais e recíprocas, de pessoas, bens, idéias, valores, entre outros, de modo a gerar uma fertilização cultural no tempo e espaço, que se reflete no patrimônio tangível e intangível.

Um itinerário, portanto, não é uma rota turística, pois seu escopo é muito maior, o turismo pode ser carregado junto, mas ele trata de forma específica de ser um recurso

6. ICOMOS 2008, p. 3 
para o desenvolvimento socioeconômico, autêntico e integro, e essas características são determinantes para sua denominação, conservação e sentido histórico. Frente a isso é importante deixar claro que o itinerário cultural não pode ser confundido com rota de turismo cultural, pois o primeiro se alicerça em processos históricos que originaram elementos patrimoniais e o segundo pode tirar proveito disso sendo projetado na base existente dentro do itinerário.

Mesmo considerando bastante rígida sua definição, pois foca os itinerários culturais como um meio de comunicação caracterizado por funcionalidade sendo resultado de movimentos interativos de pessoas em um sistema dinâmico de relações históricas de bens e fatores culturais associados à sua existência, a Carta do ICOMOS (2008) também apresenta os mecanismos fundamentais para desenvolver o conhecimento, a valorização, a proteção, a conservação e a gestão dos Itinerários culturais. Além disto, define as orientações, os princípios e os critérios principais para uma correta utilização.

$\mathrm{Na}$ carta, o aspecto mais importante de um itinerário, é que este tenha bases em uma via de comunicação entre povos; um espaço de intercambio de culturas que ocorre ao longo da história, de forma intencional ou acidental, violenta ou pacífica, consentida ou forçada pela pressão das épocas.

No caso do «itinerário cultural - Caminho para os Ervais», objeto deste trabalho, nota-se que ele serviu ao longo dos séculos como via de entrada às novas culturas, algumas vezes oriundas do Norte e em outras do Sul. Esta proposta de itinerário cultural se localiza na fronteira entre o Brasil e o Paraguai, nos limites do estado do atual Mato Grosso do Sul, no território brasileiro, com os departamentos de Amambay no Oeste e Canindeyú ao sul do Paraguai.

A Figura I mostra uma parte do caminho e a área de influência do itinerário que abarca um conjunto de 28 municípios do estado sul-mato-grossense. Região que de acordo com os dados censitários abriga 761.349 habitantes (estimativa 20I8) em um território de $87.255 \mathrm{~km}^{2}$.

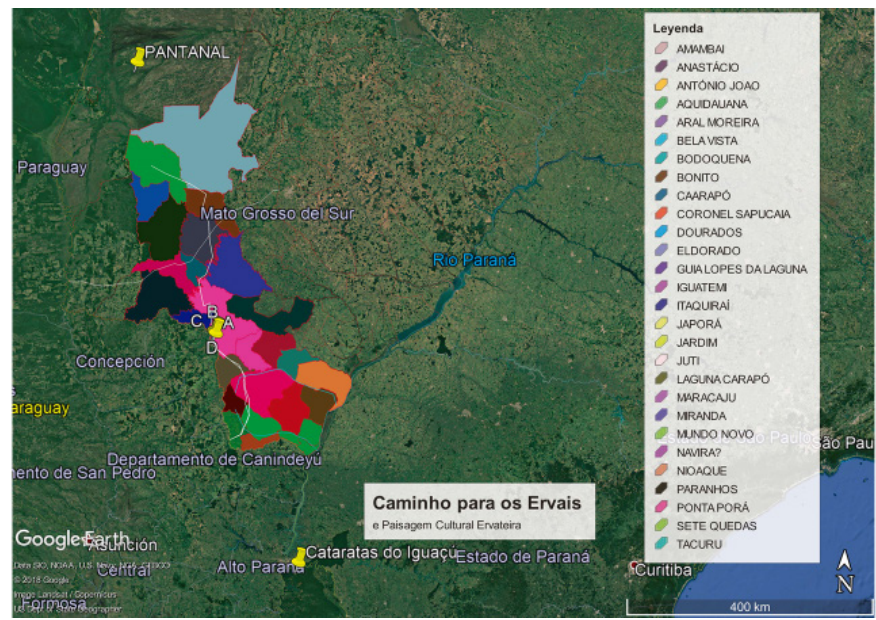

FIGURA 1- ÁREA DE ABRANGÊNCIA DO ITINERÁRIO CULTURAL CAMINHO PARA OS ERVAIS. FONTE: GOOGLE EARTH E ELABORAÇÃO PRÓPRIA

7. Dados IBGE 2010. catalogo [em linha]: <https://censo2010.ibge.gov.br/> [Consulta: 23 de agosto de 2019] 
Este artigo apresenta uma proposta de itinerário cultural denominado «Caminho para os Ervais», tendo em conta as recomendações da carta de Quebec da ICOMOS de 2008 onde a informação cientifica predomina sobre qualquer outra, por isso se faz necessário dispor de uma ferramenta que nos permita ter uma visão o mais abrangente possível que nos detecte quaisquer deficiências a serem corrigidas. Assim mesmo, temos presente as recomendações do documento do Anteproyecto de itinerarios culturales del Mercosur. Salvador, Bahia, Brasil, nos dias 23 e 24 de janeiro de 2009. Realizada sob os auspícios do Instituto de Patrimônio Histórico e Artístico Nacional (IPHAN) em 2009. Fundamental para nossa proposta já que, esse itinerário faz parte de um caminho binacional que percorre tanto Brasil como o Paraguai (Busón e Zamberlan, 2018).

Esta proposta partiu de um projeto de pesquisa da identidade cultural da fronteira de Mato Grosso do Sul, executado pelo mestrado de desenvolvimento regional e sistemas produtivos (PPGDRS) da Universidade Estadual de Mato Grosso do Sul (UEMS) com vistas a desenvolver mecanismos de desenvolvimento aptos para o território. Depois de uma etapa de identificação da realidade local se efetuou uma extensa revisão bibliográfica e cartográfica da região para conhecer sua história desde o período colonial. Nesta fase foi possível encontrar diversos materiais, documentos e mapas desde o século XVII que referendam a presença de um antigo caminho que cruzava o território de norte a Sul, que deu origem ao trabalho pós-doutoral do pesquisador Carlos B. Busón, no PPGDRS.

Este relatório de pesquisa é um avanço de pesquisas anteriores que retratam o itinerário «Caminho para os Ervais», mas ele acresce aos anteriores, principalmente pelo maior foco dado às descobertas cartográficas que dão maior autenticidade histórica e proporcionam características únicas para a proposta de itinerário cultural. Não se deixa de fazer, também, um retrato socioeconômico de fácil entendimento do território, envolvendo os municípios por onde o caminho passa ou tem influência, o que também se diferencia de outras publicações anteriores, onde há outras formas de análise.

Frente a isso, esse trabalho está estruturado em 4 seções, sendo a primeira essa introdução. Na sequência é apresentada uma breve metodologia, que norteou as ações para realização desse relatório. A terceira seção apresenta um apanhado teórico e documental sobre Itinerários Culturais e o Itinerário «Caminho para os Ervais», apresentando subdivisões que favorecem o entendimento do leitor, como uma subseção específica do Itinerário «Caminho para os Ervais» e outra que aborda os dados socioeconômicos do território que sofre a influência desse itinerário. Por fim são apresentadas as considerações finais e as referências utilizadas para dar suporte teórico e documental.

\section{METODOLOGIA}

A pesquisa se caracteriza como exploratória e descritiva, a primeira por buscar levantar informações sobre a região sudoeste do atual estado de Mato Grosso do Sul dentro de uma concepção histórica na busca de caracterização de um Itinerário, 
uma rota real, que foi utilizada por colonizadores e povos pré-colombianos; a segunda, por uma busca de descrição de aspectos socioeconômicos regionais atuais, que demonstram a importância na busca de efetivar ações que visem valorar o território e potencializar a dinâmica social e econômica da região. A fase exploratória se fez por meio de levantamentos teóricos e histórico-cartográficos e a fase descritiva por dados secundários do PNUD, no Atlas de desenvolvimento humano do Brasil.

A pesquisa é desenvolvida em duas fases, uma teórica documental, e outra de levantamento de dados secundários sobre questões econômicas e sociais que permeiam os municípios que são atingidos pelo projeto «Caminho para os Ervais». Na primeira fase, que não está finalizada, pois continua-se buscando evidências que venham a fortalecer a historicidade do itinerário, bem como possíveis aspectos culturais e étnicos que possam trazer novas informações e ainda fortalecer sua importância regional, foi elaborado um levantamento teórico de caracterização do conceito de itinerário cultural e, o mais relevante, um levantamento documental e cartográfico, buscando evidenciar a existência do itinerário como um caminho antigo, portanto, o foco das análises se deu em museus e arquivos históricos tanto no Brasil, como no exterior, facilitado por acesso em linha (on line) e pela atual digitalização de uma série de documentos de época, assim como diversas visitas a alguns de esses arquivos, como foi o caso do arquivo naval em Madri para a consulta de diversos documentos originais, alguns inclusive inéditos. Os arquivos foram procurados em diversas bibliotecas e museus digitais, como a Biblioteca Real da Espanha, Biblioteca Nacional do Uruguai, Biblioteca Nacional, que está no Rio de Janeiro, entre outros arquivos. Os arquivos selecionados fazem referência a região de fronteira Brasil/Paraguai, buscando caracterizar aspectos regionais sul-matogrossenses (estado de Mato Grosso do Sul, Brasil).

Muitos arquivos ainda não foram analisados, mas já houve várias descobertas, onde uma das maiores é o caminho antigo, que foi chamado de "Caminho para os ervais, mesmo por aparecer essa denominação em cartografia específica e, também, por a região ser caracterizada pela existência de ervais e pela exploração desses mesmos ervais em diversos períodos históricos. Essa fase documental é mais explorada nesse trabalho, pois ela é vista como elemento fundamental de autenticidade do projeto.

A segunda fase tem o intuito de chamar o leitor para a realidade regional em termos socioeconômicos, demonstrando a real necessidade de haver uma intervenção regional que busque amenizar a situação vivida pela população local, onde o Itinerário Cultural Caminho para os Ervais possa ser percebido como uma alternativa de amenizar os problemas reais observados. Para conseguir isso, fez-se um levantamento de dados secundários sobre esses aspectos compilando-os em uma figura que possibilite a rápida compreensão do contexto territorial, fazendo uso de uma série de variáveis que auxiliam a perceber a real situação da região, como índice de Gini, vulnerabilidade à pobreza, rendimento da população, taxa de envelhecimento, renda per capita da população vulnerável, entre outras, com fins de proporcionar um retrato para os municípios que compõem o projeto. 


\section{ITINERÁRIOS CULTURAIS E A PROPOSTA DO «CAMINHO PARA OS ERVAIS»}

De acordo com a Carta dos Itinerários culturais do ICOMOS de 2008, um projeto de itinerário cultural deve estar calcado em uma base cientifica, com estudos dos elementos que o compõem, considerando a rota e todos aqueles elementos patrimoniais tangíveis ou intangíveis e suas relações. Portanto, quando se abarca períodos históricos muito longos é importante uma série de estudos que busquem dar conhecimento de detalhes de intercâmbios culturais ao longo desses períodos, permitindo o entendimento de uma narrativa espacial temporal, considerando a natureza dinâmica dos sítios, do patrimônio e das paisagens.

No manual dos Conceptos Teóricos de Rutas Culturales ${ }^{8}$, este documento propõe cinco ações prioritárias que devem ser levadas em conta para o desenvolvimento de um projeto de itinerário cultural: i) definição do tópico, ou seja, a definição do itinerário em si; ii) identificação dos elementos patrimoniais; uma fase de trabalho intenso de pesquisa sobre o terreno, identificando os elementos históricos, ambientais e sociais, tangíveis e intangíveis; iii) criação de uma rede, com estatuto legal; se fará necessário elaborar entre os diferentes atores (centros de pesquisa, universidades, secretarias de estado e municipais, entre outros) uma rede para troca de informação, a fim de programar as ações para a conservação e promoção do itinerário; iv) criação de uma ação comum, onde a rede criada deverá desenvolver as estratégias de ação para defender a candidatura do itinerário a organismos como a UNESCO; e, v) criação de uma visibilidade comum; neste estágio são demandados trabalhos de sensibilização e formação dos elementos do Itinerário. A marca desse caminho o que lhe dará sua identidade própria frente a outros lugares, ou seja, um selo de autenticidade.

Segundo a Agenzia Italiana per la Cooperazione allo Sviluppo - AICS ${ }^{9}$, a tipologia dos itinerários é extensa, podendo ser de ordem geográfica, local ou regional, ou mesmo modal, terrestre, aquático ou misto.

Em seus diferentes tipos, segundo as recomendações do ICOMOS ${ }^{\text {Io }}$, os itinerários culturais devem apresentar elementos que os definem:

I. Contexto: os Itinerários culturais inscrevem-se num contexto natural e/ou cultural, no qual incidem, contribuindo para a sua caracterização e enriquecimento com novas dimensões, no quadro de um processo interativo.

2. Conteúdo: devem apoiar-se necessariamente sobre os elementos patrimoniais tangíveis que constituem os testemunhos e a confirmação física da sua existência.

8. Instituto Europeo de Itinerarios Culturales, Luxemburgo. MÓDULO I : CONCEPTOS TEÓRICOS DE RUTAS CULTURALES, projeto V.E.R.N.E. («Vocational Education for European Routes Networks») do Instituto Europeo de Itinerarios Culturales (IEIC). Extracto de la gestión de rutas culturales. De la teoría a la práctica paso a paso guía a los Itinerarios Culturales del Consejo de Europa - Penélope Denu, Eleonora BERTI [em linha]: <http:// ponorte.com/downloads/verne/1.MODULO-1_RUTAS-CULTURALES.pdf> [Consulta: 23 de agosto de 2019].

9. Guía metodológica para la elaboración de itinerarios culturales 2016, p. 10, 11

10. ICOMOS 2008, p. 4,5 
Os elementos intangíveis dão ao conjunto dos elementos concretos, um sentido e uma significação.

3. Valor de conjunto partilhado: o conceito de Itinerário cultural refere-se a um conjunto de valor superior à soma dos elementos que o constituem e que lhe dão sentido.

4. Caráter dinâmico: para além de se afirmar através de um traçado histórico de caráter físico e de elementos patrimoniais, os Itinerários culturais implicam um fator de dinamismo que age como um fio condutor através do qual agiram as influências culturais recíprocas.

5. Meio: o ltinerário cultural está estreitamente ligado ao seu meio, do qual faz parte integrante.

A discussão de itinerários é corroborada por Martorell Carreño (20Io) onde ele recomenda uma série de passos onde se parte da necessidade de um projeto, da reconstrução científica do itinerário, do inventário de elementos patrimoniais, da divulgação científica, acadêmica e institucional, da educação para sua conservação, da sua restauração e implementação de sítios, entre outros. Esses passos, aqui sintetizados, mostram a complexidade do trabalho de criar ou revitalizar um itinerário cultural. Sendo necessários a criação de equipes interdisciplinares que estudem todas as variáveis necessárias para instaurar essa iniciativa.

A promoção dos territórios, por meio de sua patrimonialização é o motor da criação, regate e consolidação dos itinerários culturais. Se fazem necessárias ações educativas na sociedade com o fim de que esta assuma o valor cultural local como algo próprio a ser preservado e valorizado. Quando se aborda desenvolvimento o elemento cultura é visto também como um bem que pode ser utilizado no saneamento de problemas socioeconômicos dos territórios, como se observa no Relatório mundial da UNESCO (2009). Fischer (2012), considera que a cultura e a diversidade cultural de um país, são grandes ativos, por fazerem parte da constituição do patrimônio, nesse caso entendido por Silva (2000) dentro de uma ideia de posse, de algo de valor atribuído por um indivíduo ou sociedade.

Os itinerários culturais possuem um patrimônio, que em muito pode estar perdido na história, mas que possui valor e que pode ser recuperado e direcionado para o saneamento de problemas estruturais de um ou vários territórios e, com isso, tendo potencialidades de impacto no desenvolvimento regional ou local. Nesse sentido, os itinerários culturais são vistos como depósitos patrimoniais que podem ser utilizados para diferentes coletivos humanos e com distintos valores a eles atribuídos.

\section{A PROPOSTA «CAMINHO PARA OS ERVAIS}

Este breve resgate orienta as discussões que seguem essa proposta de Itinerário Cultural, mesmo que de forma incipiente. No espaço em estudo, a erva mate ${ }^{\text {II }}$ mar-

11. A llex paraguasensis (1822) catalogada pelo botânico francês Augustin François de Saint-Hilaire é uma espécie 
cou a trajetória histórica e econômica da região sul-mato-grossense (presente-I979), ou do antigo sul de Mato Grosso (I979-I870) e anteriormente o Paraguai (I870-I8II) e os antigos territórios da província de Paraguai nos Vice-Reinos controlados pela coroa espanhola (I8II- I5I6). Além de ser região endêmica da erva mate, com registros da sua exploração na região da nossa pesquisa já no século XVII, indicando que era uma região rica em ervais. Não podemos esquecer que o uso da erva mate, já era amplamente conhecido e utilizado pelas nações indigenas desde muito antes do período colonial, transmitindo a cultura da sua utilização a todos povos que entravam no território. Este elemento marcou profundamente a região ao final do século XIX e princípios do XX, sendo o fator que desencadeou importante etapa de colonização do território, o que ocorreu a partir da concessão territorial para a Cia. Matte Laranjeiras, que permitiu a exploração dos ervais e também da mão-de-obra local, principalmente indígenas e paraguaios de mesma origem.

Tendo em vista a tipologia anteriormente apresentada, o itinerário cultural «Caminho para os Ervais», se classifica em termos de dimensão territorial, a uma dimensão regional ${ }^{12}$ (em especial na faixa de fronteira). É um caminho misto, com grande parte terrestre, que liga a região do Pantanal, percorrendo o Sudoeste até o Sul de MS, na região de Paranhos depois utilizando os rios Iguatemi e Amambai para ligar ao rio Paraná. Nisso, abrange diversas áreas, desde as regiões históricas de povos indígenas até os núcleos de colonizadores do século $\mathrm{XX}$ vindos do sul do Brasil. Além disto, é uma região de fronteira entre o Brasil e Paraguai, com contínuo processo de influências recíprocas entre os povos das duas nações. Na dimensão temporal se encontra em uso, mas sem a consciência histórica de seu uso ao longo dos séculos, dado os registros descritos em documentos do século XVII. Neste sentido, se faz necessário uma recuperação histórica detalhada seguindo uma explicação a comunidade a importância cultural deste trajeto/itinerário, auxiliando em um processo de criação de identidade.

O Itinerário cultural Caminho para os Ervais cumpre com o requisito de ter sido uma via de comunicação. Para Gadelha (2013), este trajeto foi uma via de conexão entre o sul e o norte, ao longo dos séculos, entre as duas grandes bacias hidrográficas do Rio Paraná e Paraguai. Existe indicativo de que durante a época pré-colonial o trajeto deste Itinerário fazia parte da rede de comunicação local sendo um ramal na direção Norte-Sul do caminho Peabiru, que conectava o oceano Atlântico com o Pacífico. Tinha aproximadamente uns oito palmos de largura estando coberto por diversas espécies de gramíneas que impediam o crescimento de outras espécies vegetais, segundo se conta era utilizado pelos povos guaranis no seu caminho em busca do Yvy Marae'y ou Tierra Sin Mal. Para os espanhóis e portugueses essas rotas constituíam caminhos reais nos quais as coroas espanhola e portuguesa recorriam para conhecer e ampliar seus domínios.

endêmica da região. Seu uso e exploração se remonta a os povos ancestrais. Existem registros da sua exploração na região que se remontam ao século XVII.

12. O caminho no Brasil recorre o território de sul a norte no Estado do Mato Grosso do Sul. Entrando no Brasil através do departamento de Canindeyú no município de Paranhos ao sul do Estado e recorrendo o território paralela a fronteira do Brasil com o Paraguai com o departamento de Amambay. 
«Inúmeros autores se debruçaram sobre o tema das bandeiras, ressaltando a comunicação e os contatos entre as populações pré-colombianas do Brasil e do Paraguai, através das trilhas do Tape Aviru ou Piabiru Tupi-Guarani - chamada Estrada Real pelos portugueses. No século XVI estas trilhas conduziam por terra e por rios, índios, missionários e colonizadores, desde São Vicente até Assunção e vice-versa. Sem falar na atração que exercia sobre os comerciantes, contrabandistas e aventureiros, atraídos pela prata de Potosi». ${ }^{13}$

O Caminho para os Ervais mostra ter autenticidade histórica e está localizado em um território que foi bastante disputado ao longo dos séculos ${ }^{14}$. A sua situação geoestratégica permitia uma fácil circulação entre as bacias do Paraná e Paraguai e entre diversos povos evitando a navegação pelos rios, que no período das chuvas tornava a navegação muito difícil como testemunham algumas crônicas da época. Assim mesmo, os ataques dos povos indígenas Payaguas que habitavam a parte superior do rio Paraguai faziam que outros povos evitassem circular nele.

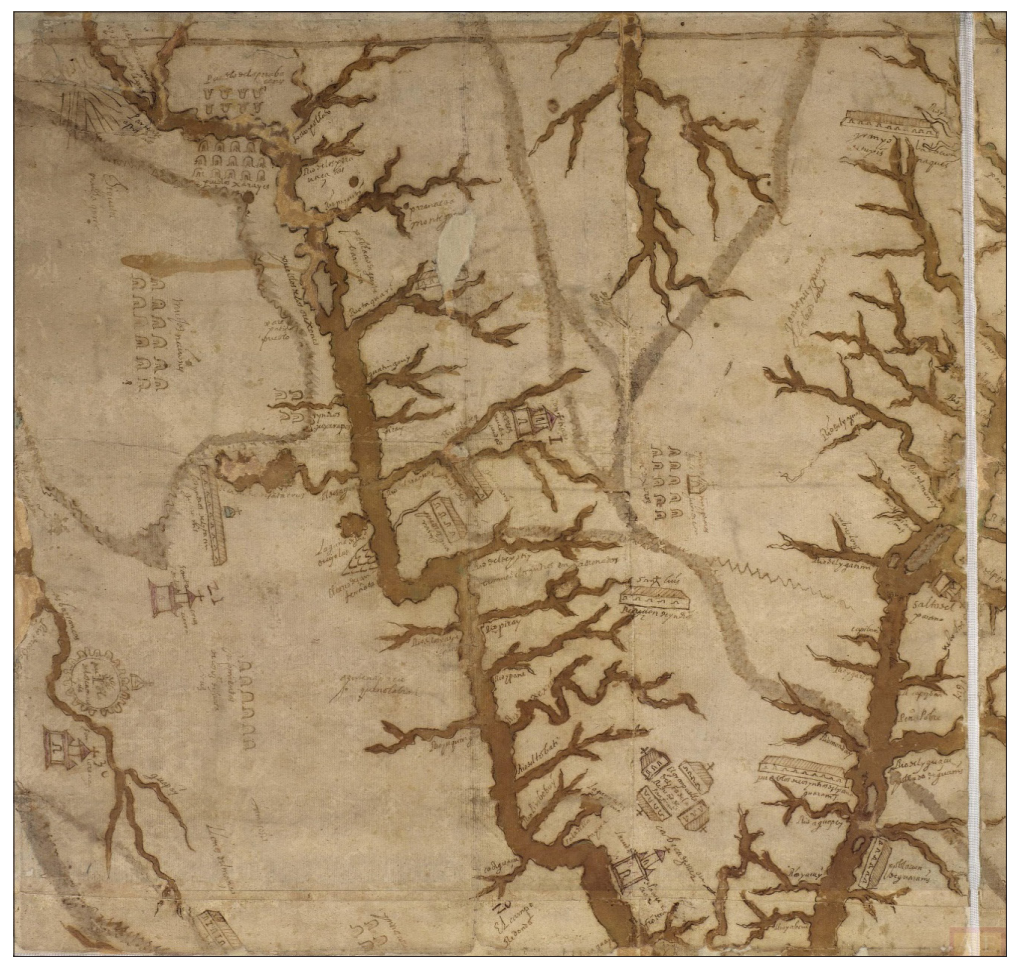

FIGURA 2. DETALHE DO «MAPA DE AMÉRICA DEL SUR DESDE EL ECUADOR HASTA EL ESTRECHO DE MAGALLANES». Fonte: Archivo General de Indias (Sevilla, España) Consejo de Indias (España) Código de Referencia: ES.41091.AGI/27.3//MP-BUENOS_AIRES,4.Catálogo [em linha]<http://pares.mcu.es/ParesBusquedas2o/ catalogo/description/16777> [Consulta: 23 de Agosto de 2019]

13. Gadelha 2013, p. 7

14. Este território foi recorrido e cartografado com bastante detalhe pela primeira comissão de limites do tratado de Madri de 1750. Posteriormente pelos demarcadores para o tratado de San Idelfonso de 1777 pela segunda comissão a cargo de Félix de Azara. Segundo Martín-Merás (2007) existe uma abundante informação cartográfica e documental sobre essas comissões de limites durante o século XVIII no Museu Naval de Madri.

Pudemos pesquisar os fundos digitais do organismo dos quais utilizamos alguns documentos. Não obstante se faz necessário aprofundar a pesquisa in situ para as seguintes fases do projeto. 
Diversos estudos foram realizados sobre estes caminhos como o de Holanda (2010) na sua obra Visão do Paraíso: Os motivos edênicos no descobrimento e colonização do Brasil. Que nos serviu como indutor para aprofundar no conhecimento de essas primitivas rotas de entrada do território. Voltando aos povos originários, estes eram os caminhos utilizados pelos indígenas sul-americanos desde épocas remotas. Ruy Díaz de Guzmán e Irala já descrevia sua utilização na sua obra Historia argentina del descubrimiento, población y conquista de las provincias del Río de la Plata, em I6I2. Ademais temos o mapa atribuído a este autor da segunda metade do século XVII (Figura 2) em que se observa toda essa rede de caminhos. Dito documento se encontra no Arquivo das Índias na Espanha.

Na obra Historia de la conquista del Paraguay, Río de la Plata y Tucumán escrita por el P. Pedro Lozano; ilustrada con noticias del autor y con notas y suplementos recopilada por Andrés Lamas (I8I7-I89I) nos mostra os escritos de Pedro de Lozano (I697I752). No início do século XVIII descreve essa rede de caminhos da seguinte forma:

\footnotetext{
«Por esta provincia corre el camino nombrado por los guaranís peabirú y por los españoles de Santo Tomé, que es el que trajo el gloriosísimo apóstol por más de 200 leguas, desde la capitanía de San Vicente, en el Brasil, y tiene ocho palmos de ancho, en cuyo espacio solo nace una yerba muy menuda que le distingue de toda la demás de los lados, que por la fertilidad crece á media vara, y aunque agostada la paja, se quemen los campos, nunca la yerba del dicho camino se eleva más, en reverencia sin duda de las sagradas plantas que la hollaron, y para testimonio de las fatigas que en tierras tales padecería el apóstol primero de la América.» ${ }^{15}$
}

Techo (I897) descreve algumas das características específicas da cobertura vegetal nesse caminho:

\footnotetext{
«Los viajeros que van del Brasil al Guairá pueden ver todavía la senda de Santo Tomás, por la que él anduvo; se conserva igual todo el año, sin más que las yerbas crecen algo y difieren bastante de las que hay en el campo, ofreciendo el aspecto de una vía hecha con artificio; jamás la miran los misioneros del Guairá que no experimenten grande asombro. Además, cerca de la capital del Guairá hay elevados peñascos coronados de pequeñas planicies en las que se ven grabadas sobre la roca huellas humanas;» 16
}

Percebe-se a existência novamente de autenticidade desse itinerário, mas salienta-se que serão necessárias pesquisas de campo para determinar com maior exatidão o roteiro original desse caminho em toda sua extensão desenvolvendo uma cartografia dos caminhos e rotas primitivas utilizadas, e todos os outros recursos, a ser inventariados e preservados, pois muito da paisagem original foi alterada pela agricultura extensiva assim como as estradas e caminhos que possivelmente coincidem com o antigo traçado. Os estudos arqueológicos assim como de outras técnicas, como

15. Lamas 1873, p. 67

16. Trecho 1897, p. 22 
poderiam ser estudos de paleobotânica podem ser ferramentas importantes para se determinar a presença dessas espécies de gramíneas citadas acima.

Ademais, o resgate histórico aponta que o caminho permitia a circulação dos povos indígenas, mas também permitiu a entrada durante o período colonial de novas influências sobre o território. O caminho estava lá e era a melhor forma de circular por um território desconhecido e cheio de florestas.

Dentro dessa proposta de itinerário observa-se a coexistência da tradição ancestral indígena do consumo da erva mate, na forma inicial de mate e, posteriormente do tereré, infusão em água gelada da erva mate beneficiada por meio de moagem e processos de secagem, como consta nos registros de Pedro de Montenegro em ${ }{ }^{7} \mathrm{II}^{17}$. Ademais, somam-se a essa tradição, o uso dos tradicionais «yuyus» (ervas medicinais utilizadas na infusão com erva mate).

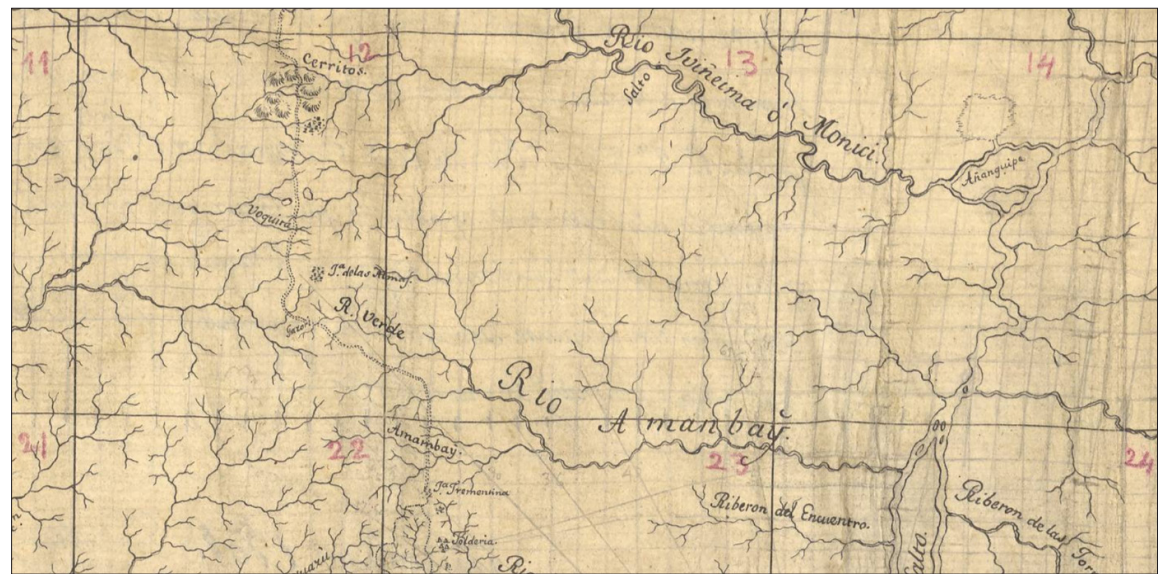

FIGURA 3. BVPB. DETALHE DO «PLANO DEL VIRREINATO DE BUENOS AIRES EN EL QUAL SE HALLA REMARCADA LA LINEA DIVISORIA Y LOS MARCOS QUE EN ELLA SE PUSIERON DESDE CASTILLOS EN LA COSTA DEL MAR HTA LA BSOCA DEL JAURY POR LA 2A 3A Y 4A PARTIDA DE LA DEMARCACN DE 1759 / YAN DEBIO SER TRAZADO ESTE MAPA CON AREGLO A LOS ELEMENTOS Y NOTICIAS QUE ADQUIRIERON EN AQUEL ENTONCES ESTOS DEMARCADORES Y LAS PARTES POR DONDE HIZIERON SUS VIAJES COMO EL PARANA, PARAGUAY, IGATIMI SERAN PARTICULARMENTE DESIGNADAS CON BASTANTE ESXACTITUD HAVIENDO ESTADO EMPLEADO EL DHO CUSTODIADO POR PARTE DE PORTUGAL EN LA EXPRESADA DEMARCACIÓN ; COPIADO EN 1801 PARA HIDROGRÁFICO DE MADRID»

Evidencia-se, ao longo do caminho proposto a incorporação de tradições espanholas que deram hibridismo a cultura local, a cultura paraguaia e uma cultura mestiça que incorporou elementos provenientes de diversas culturas indígenas, paraguaia e brasileira. Esse processo de interação dinâmico, são vivenciados no espaço de fronteira entre Brasil e Paraguai atualmente, marcado por extensa faixa de fronteira, que em muitos momentos se confunde com o próprio traçado do itinerário.

17. Encontramos uma obra manuscrita sobre plantas medicinais do padre Jesuíta Pedro de Montenegro (16631728) com o título «Libro primero de la propiedad y virtudes de los árboles y plantas de las misiones y provincia del Tucumán, con algunas del Brasily del Oriente: dividido en dos libros, en el primero se trata de la propiedad y virtudes de los árboles y de las plantas menores [...] en el segundo de las hierbas y raíces comestibles... compuesto por el hermano Pedro de Montenegro, de la Compañía de Jesús, año de 1711, en las Misiones del Paraguay». Biblioteca Nacional de Madrid. Catálogo [em linha] <http://bdh-rd.bne.es/viewer.vm?id=0000042551\&page=1> [Consulta: 23 de agosto de 2019] 
A análise dos documentos cartográficos, da primeira comissão de limites consequência do tratado de Madri, do espanhol Andrés de Oyarvide e do português José Custodio de Sáa e Faria (1759) indicam a presença desse itinerário, um caminho de acesso ao território. Alguns destes arquivos são apresentados abaixo, embora seja uma pesquisa ainda em construção o traçado é bastante evidente, como se observa nas Figuras de 3 e 4.

Assim mesmo, é possível ver a descrição do caminho em documentos escritos como a carta de Manuel Antônio De Flores, dirigida ao Marques de Valdelirios, escrita em Buenos Aires, em I4 de Agosto de I756. Descreve-se com bastantes detalhes desse caminho real e como era utilizado na época.

«No ha muchos años que hicieron este viage los Paulistas corsarios de Indios subiendo por el rio de Amambay, en el que hallaron, antes de llegar á su interseccion con el camino real, dichos saltos y arrecifes que salvaron por tierra; y guiados del mismo camino, llegaron á los términos de Curuguatí, de donde se volvieron sin hacer cosa notable. Pueden tambien del Paraná subir por el rio Igatimí, que es el término de la linea y el mas inmediato a Curuguatí, hasta encontrar con el mismo camino real. La escuadra de trece canoas grandes que desde San Pablo vino á este paso para conducirnos al Salto Grande del Paraná, tardó en este viaje 81 dias, como se ve en el diario de la demarcacion. Tiempo antes lo habian hecho los Paulistas de quienes se habló antecedentemente que no queriendo entrar por el Amambay, que ya conocian, subieron por Gatimí, venciendo con bastante trabajo, los arrecifes que por espacio de 7 leguas tiene, y de que se dió noticia en el diario ya citado. Hicieron por tierra el camino que les faltaba para llegar á los términos de Curuguatí y se establecieron en una campiña, que conocen los vecinos bajo del nombre de la Tapera de los Portugueses. Sembraron algunas semillas y se mantuvieron allí, hasta que, recelosos de una corrida de gente que mandó hacer el gobernador del Paraguay para desalojarlos con noticia que tuvo de su establecimiento, huyeron á sus canoas, y se volrieron sin haber parecido mas. Despues de esta expulsión, salen por órden de la Corte todos los años los vecinos ó milicias de Curuguatí, á reconocer las campañas, para impedir á los Portugueses que se establezcan en estos términos, que hasta la determinación de la Frontera por el tratado de límites, han tenido por indefinidos, y será muy conveniente que continúe en dicha práctica para que vean la raya, que conocen bien aquellos vecinos: porque á este fin saqué cincuenta de los principales, que me acompañaron y sirvieron de escolta en mis viajes para la demarcacion.

53 - El camino real por donde hacen los Curuguatines estas corridas, alcanza hasta las inmediaciones de Camapuán, y aunque nunca llegaron á este sitio despues que los Portugueses se poblaron en él, pero anduvieron tan cerca que en varias ocasiones llegaron á ver los humos que creyeron fuesen de los indios montarases, ignorando que pudiesen los Portugueses tener establecimiento en aquel paraje tan inmediato. Por esto se vé que subiendo por el Rio Pardo á Camapuán como lo hacen hoy en su navegacion á Cuyabá, pueden por el mismo camino real ó por otro nuevo que pueden abrir con el tiempo, venir por tierra á Curuguatí: y en otros casos harán el viaja con mas ó menos brevedad, segun el Rio que tomen, avios y disposiciones que tengan.» ${ }^{18}$

18. De Angelis 1836, p. 24, 25 
Para finalizar a aproximação histórica do Itinerário nos encontramos com os materiais levantados já no século XIX pela última comissão de limites depois da guerra Guaçu ou da tríplice Aliança entre os comissários do Brasil e Paraguai. No mapa do Mato Grosso de 1876 percebe-se detalhadamente toda uma rede de caminhos que faz parte dessa proposta de trabalho. Esses caminhos foram usados para a exploração de erva mate ao final do século XIX e princípios do XX e servindo como rota de entrada das novas levas de colonos provenientes do sul do Brasil que se assentavam no território.

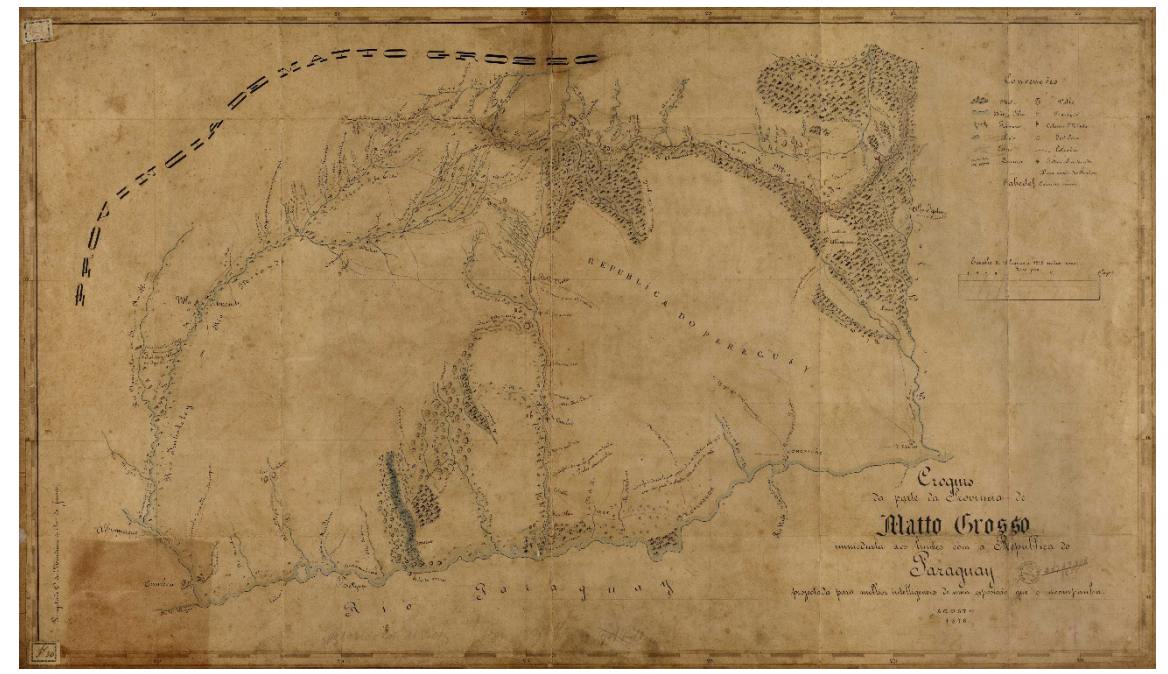

FIGURA 4. BNDIGITAL. CROQUIS DA PARTE DA PROVÍNCIA DE MATTO GROSSO IMEDIATA AOS LIMITES COM A REPÚBLICA DO PARAGUAY PROJECTADA PARA MELHOR INTELLIGÊNCIA DE UMA EXPOSIÇÃO QUE O ACOMPANHA. 1876. 1 MAPA MS, COL, 48,5 X 85CM EM FOLHA DE $52 \times 89$

Nessa cartografia é permitido observar toda a rede de caminhos que foi utilizada para pensar a proposta caminho para os ervais, incluindo o nome dado ao projeto, que consta na figura como Caminho para os Ervais. No entanto, esta é a proposta inicial, o mapa mostra outras possibilidades de itinerários que podem se vincular ao proposto inicialmente, e, ainda, fortalecê-lo. Encontra-se nele diversos caminhos que podem ser melhor explorados como o caminho que passa, por exemplo, pelas colônias de Dourados e Miranda, pelo Forte Coimbra, que foram locais importantes na formação do território brasileiro e sul-mato-grossense. Fora isso, é possível ver o caminho que chega a Cerro Corá, local onde Francisco Solano Lopes ${ }^{19}$, foi morto ao fim da Guerra Guaçu ${ }^{20}$ ao enfrentar as tropas brasileiras lideradas pelo Conde D’Eu.

19. Francisco Solano López Carrillo (1827-1870) foi o segundo presidente da República do Paraguai entre 1862 e 1870. Era filho de Carlos Antonio López (1792-1862), primeiro presidente do Paraguai. O Marechal Francisco Solano López utilizou o caminho do nosso estudo na sua retirada com os restos do ejercito paraguaio e centenares de refugiados frente as tropas brasileira durante a campanha das cordilheiras, durante a quinta e ultima fase da Guerra do Paraguai. É possivel acompanhar essa retirada nos mapas da obra Atlas historico da guerra do Paraguay realizado por Emilio Carlos Jourdan (1838-1900). Publicado no Rio de Janeiro pela Lithographia Imperial de Eduardo Rensburg em 1871.

20. Guerra Guaçu, Guerra do Paraguai ou Guerra da tríplice aliança foi o conflito bélico que enfrentou o Paraguai contra o Brasil, Argentina e Uruguai entre Dezembro de 1864 a Março de 1870. 
Esse mesmo Caminho, também foi utilizado para escoar a produção da erva mate das terras brasileiras para o porto de Concepción, sede da Companhia Matte Laranjeira, no Rio Paraguai, onde seguia para Argentina, no período posterior a Guerra Guaçu.

A Cia. Matte Laranjeira teve a concessão para explorar todo o território do Sul de Mato Grosso por parte do Império Brasileiro em virtude dos serviços prestados por seu proprietário Thomaz Laranjeira, durante a Guerra do Paraguai, o que na verdade não passou de uma cessão de monopólio e de privilégio pelo personalismo que se institucionalizou no Brasil e foi bem retratado por Sérgio Buarque de Holanda no conceito de Homem Cordial, em Raízes do Brasil, I995. Thomaz Laranjeira mudou a sede para Porto Murtinho, em território do Sul de Mato Grosso e posteriormente para Guaíra, atualmente no estado do Paraná (Brasil), sendo responsável pela criação dessas duas cidades.

Atualmente, a cidade de Porto Murtinho é ligação com o Paraguai para o projeto da Rota Bioceânica, também conhecida como Rota de Integração Latino Americana (RILA), um projeto que busca uma ligação logística, por via rodoviária entre os Portos de Paranaguá (Paraná - Brasil), no Oceano Atlântico e o Porto de Antofagasta (Chile), no Oceano Pacífico, passando por território Paraguaio e Argentino, além do território brasileiro, inclusive encontrando o que denominamos «Caminho para os Ervais», sendo, também, uma futura possibilidade de exploração cultural e, também turística.

\section{DADOS SOCIOECONÔMICOS DOS MUNICÍPIOS DO «CAMINHO PARA OS ERVAIS»}

Os municípios que estão na região de abrangência do Caminho para os Ervais são economicamente heterogêneos. Quando se analisa o Produto Interno Bruto (ano 20I5), é possível observar municípios que se classificam entre primeiras economias do estado (Dourados $\left(3^{\mathrm{a}}\right)$ e Ponta Porã $\left(5^{\mathrm{a}}\right)$, Maracajú $\left(6^{\mathrm{a}}\right)$ ao passo que outros se classificam nas últimas posições (Coronel Sapucaia $\left(63^{\mathrm{a}}\right)$, Juti $\left(65^{\mathrm{a}}\right)$, Paranhos $\left(70^{\mathrm{a}}\right)$ e Japorã $\left(79^{\mathrm{a}}\right)$.

A tabela abaixo apresenta alguns indicadores sobre as condições socioeconômicas dos municípios que estão na região em análise. Em relação à alocação do pessoal ocupado por grandes setores, observa-se uma predominância (algo próximo a 50\%) da alocação nos setores de comércio e serviços, embora algumas cidades se destacam no setor de agropecuário (com \% acima de 30\%), como por exemplo Antônio João, Aral Moreira, bela Vista, Iguatemi, Itaquiraí, Japorã, Laguna Carapã, Miranda, Nioaque e Tacuru.

O rendimento médio dos ocupados com I8 anos ou mais para a região é de R\$ 985,2I uns 239 USD ${ }^{21}$. O menor rendimento é registrado em Japorã ( $\mathrm{R} \$ 626,27$ uns I52 USD) e o mais elevado em Dourados (R\$ I466.96 uns 356 USD). De acordo com os dados do Atlas, em 2010, os municípios do Caminho para os Ervais representavam $29 \%$ a População Economicamente Ativa do estado de Mato Grosso do Sul com I8 anos ou mais.

21. $\mathrm{IUSD}=4,057 \mathrm{BRL}$, cambio a 23 de Agosto de 2019 
TABELA I - INDICADORES SOCIOECONÔMICOS DOS MUNICÍPIOS SELECIONADOS

\begin{tabular}{|c|c|c|c|c|c|c|c|c|c|c|c|}
\hline 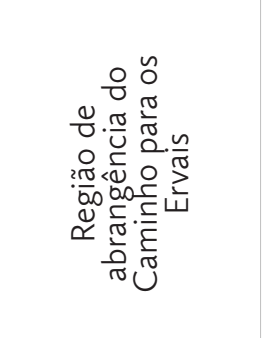 & 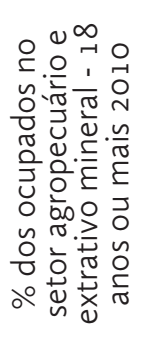 & 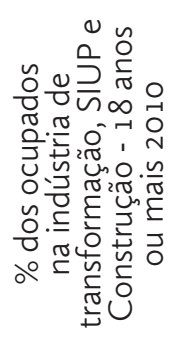 & 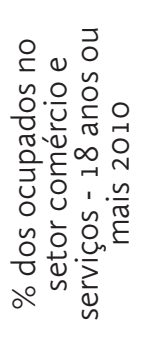 & 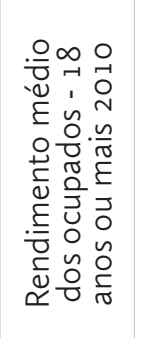 & 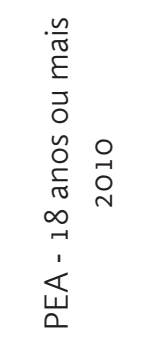 & 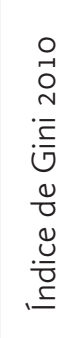 & 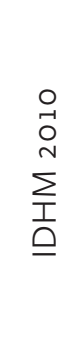 & 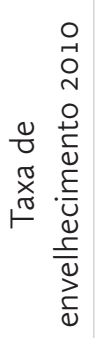 & 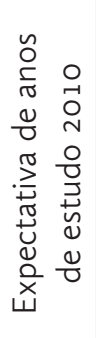 & 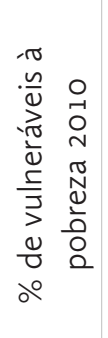 & 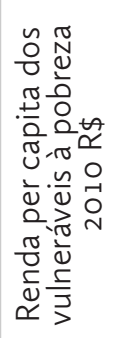 \\
\hline Amambai & 20.67 & 14.02 & 58.64 & 1100.24 & 14805.00 & 0.56 & 0.67 & 6.68 & 8.87 & 40.97 & 132.92 \\
\hline Anastácio & 20.86 & 17.88 & 57.34 & 874.55 & 11027.00 & 0.47 & 0.66 & 7.59 & 10.12 & 38.42 & 159.74 \\
\hline Antônio João & 36.81 & 11.13 & 50.66 & 789.16 & 3415.00 & 0.54 & 0.64 & 7.48 & 9.81 & 51.88 & 136.87 \\
\hline Aquidauana & 19.90 & 13.88 & 61.14 & 1075.80 & 19090.00 & 0.56 & 0.69 & 8.13 & 9.55 & 40.94 & 148.46 \\
\hline Aral Moreira & 37.52 & 8.83 & 47.71 & 813.67 & 4062.00 & 0.53 & 0.63 & 5.11 & 8.98 & 54.63 & 143.25 \\
\hline Bela Vista & 30.41 & 10.03 & 58.18 & 1053.38 & 10420.00 & 0.61 & 0.70 & 7.74 & 10.08 & 46.66 & 154.21 \\
\hline Bodoquena & 26.28 & 14.87 & 51.57 & 936.14 & 3613.00 & 0.50 & 0.67 & 6.02 & 10.97 & 41.26 & 152.85 \\
\hline Bonito & 24.90 & 12.51 & 59.77 & 1112.29 & 9928.00 & 0.54 & 0.67 & 5.95 & 9.50 & 32.00 & 175.04 \\
\hline Caarapó & 26.69 & 22.95 & 47.80 & 1008.33 & 11456.00 & 0.50 & 0.69 & 6.70 & 9.10 & 34.45 & 126.98 \\
\hline Coronel Sapucaia & 27.51 & 16.76 & 49.83 & 822.29 & 4867.00 & 0.55 & 0.59 & 6.04 & 8.25 & 57.56 & 117.67 \\
\hline Dourados & 6.91 & 21.04 & 66.56 & 1466.96 & 97528.00 & 0.52 & 0.75 & 6.03 & 10.01 & 19.88 & 171.83 \\
\hline Eldorado & 24.22 & 16.90 & 55.59 & 940.07 & 5437.00 & 0.49 & 0.68 & 7.09 & 9.11 & 35.56 & 158.19 \\
\hline $\begin{array}{l}\text { Guia Lopes } \\
\text { da Laguna }\end{array}$ & 29.13 & $17 \cdot 50$ & 53.24 & 1086.95 & 4306.00 & 0.57 & 0.68 & 9.53 & 10.27 & 42.83 & 145.71 \\
\hline Iguatemi & 30.09 & 16.14 & 51.85 & 963.81 & 6471.00 & 0.51 & 0.66 & 6.55 & 8.87 & 38.15 & 159.16 \\
\hline Itaquiraí & 46.00 & 12.80 & 36.25 & 692.21 & 7797.00 & 0.50 & 0.62 & 6.00 & 9.56 & $44 \cdot 35$ & 141.59 \\
\hline Japorã & 56.35 & 6.92 & 34.86 & 626.27 & 2070.00 & 0.66 & 0.53 & 5.98 & $7 \cdot 30$ & 72.04 & 74.99 \\
\hline Jardim & 17.26 & 16.59 & 65.24 & 1253.78 & 11447.00 & 0.55 & 0.71 & 7.94 & 10.04 & 30.16 & 155.89 \\
\hline Juti & 23.04 & 14.24 & 50.86 & 921.05 & 2103.00 & 0.51 & 0.62 & 8.97 & 10.08 & 41.08 & 121.13 \\
\hline Laguna Carapã & 45.03 & 11.74 & 42.17 & 1054.91 & 2818.00 & 0.53 & 0.67 & 6.46 & 9.24 & 38.64 & 129.00 \\
\hline Maracaju & 21.22 & 18.96 & 53.79 & 1361.49 & 17966.00 & 0.54 & 0.74 & 4.65 & 9.75 & 22.82 & 153.61 \\
\hline Miranda & 31.07 & 14.87 & $49 \cdot 50$ & 842.55 & 10107.00 & 0.54 & 0.63 & 6.15 & 8.62 & 52.85 & 138.88 \\
\hline Mundo Novo & 15.58 & 23.55 & 57.74 & 1119.71 & 8072.00 & 0.50 & 0.69 & 8.75 & 9.42 & 29.41 & 164.03 \\
\hline Naviraí & 11.20 & 30.39 & 53.87 & 1171.00 & 23189.00 & 0.47 & 0.70 & 5.65 & 10.31 & 21.48 & 170.35 \\
\hline Nioaque & 44.10 & 12.17 & 43.48 & 884.44 & 6438.00 & 0.58 & 0.64 & 6.46 & 9.38 & 49.78 & 127.70 \\
\hline Paranhos & 26.34 & 11.44 & 52.97 & 773.47 & 3343.00 & 0.64 & 0.59 & 5.38 & 8.78 & 69.58 & 87.33 \\
\hline Ponta Porã & 21.06 & 14.82 & 63.19 & 1161.75 & 36111.00 & 0.60 & 0.70 & 5.92 & 9.94 & 40.10 & 150.39 \\
\hline Sete Quedas & 29.96 & 16.82 & 52.20 & 874.13 & 4494.00 & 0.54 & 0.61 & 8.72 & 8.20 & $45 \cdot 32$ & 142.25 \\
\hline Tacuru & 39.64 & 10.55 & 41.82 & 805.37 & 3300.00 & 0.60 & 0.59 & 6.04 & 8.41 & 57.54 & 112.15 \\
\hline Média & 28.21 & 15.37 & 52.42 & 985.21 & 12345.71 & 0.54 & 0.66 & 6.78 & 9.38 & 42.51 & 141.15 \\
\hline Desvio padrão & 11.09 & 4.94 & 7.89 & 196.07 & 18324.77 & 0.05 & 0.05 & 1.24 & 0.79 & 12.82 & 23.54 \\
\hline $\begin{array}{l}\text { Coeficiente de } \\
\text { Variação }\end{array}$ & $39 \%$ & $32 \%$ & $15 \%$ & $20 \%$ & $148 \%$ & $9 \%$ & $7 \%$ & $18 \%$ & $8 \%$ & $30 \%$ & $17 \%$ \\
\hline
\end{tabular}

Fonte: Atlas do Desenvolvimento Humano no Brasil, 2010, PNUD ${ }^{22}$. Dados selecionados pelos autores.

22. Atlas do Desenvolvimento Humano no Brasil. [em linha]: <http://atlasbrasil.org.br/2013/> [Consulta: 23 de Agosto de 2019] 
O Îndice de Gini mede o grau de desigualdade existente na distribuição de indivíduos segundo a renda domiciliar per capita. Quando seu valor se aproxima de zero, significa que a renda domiciliar per capita de todos os indivíduos têm o mesmo valor e quando se aproxima da unidade a desigualdade é máxima. Os valores observados apontam um valor médio do coeficiente de o,66, acima do Índice estadual para o mesmo período $(0,56)$ o que indica que nesta região há maior concentração quando comparada com a média estadual.

Por sua vez, o Índice de Desenvolvimento Humano Municipal aponta Japorã com a cidade de menor IDHM e Dourados com o maior indicador, o que pode ser resultado de uma correlação existente com a característica populacional de Japorã, que é, em sua maioria, composta por indígenas - o que acontece nas demais cidades do território com características semelhantes - que foram excluídos nos processos históricos de formação regional de todas as políticas de desenvolvimento brasileiras, que priorizaram aos imigrantes brancos e seus descendentes. Porém em sua maioria as cidades selecionadas não se aproximam do IDHM médio no estado $(0,729)$. Estes indicadores reforçam a importância da implantação deste itinerário cultural como ferramenta de desenvolvimento.

Ademais, quando se analisa a proporção de vulneráveis à pobreza, isto é, indivíduos com renda domiciliar per capita igual ou inferior a $\mathrm{R} \$ 255,00$ mensais ${ }^{23}$ (aproximadamente uns 2\$USD dia), observa-se que em média 42,5I\% da população encontram-se nesta condição, com rendimento médio de R \$ I4I,I5 mensais. Porém, algumas cidades têm índices alarmantes, com aproximadamente $70 \%$ da população vivendo nesta condição, com renda inferior a $\mathrm{R} \$ 88,00$ mensais como o caso de Paranhos e Japorã (R 74,99 , que não chega a I \$UDS dia). Neste sentido, são emergentes ações integradoras que fomentem as economias locais considerando suas especificidades culturais identitárias e em atividades menos concentradoras e que possibilitem a redução da vulnerabilidade socioeconômica presente no território.

\section{CONSIDERAÇÕES FINAIS}

Este estudo objetivou apresentar o projeto caminho para os ervais, uma proposta de itinerário cultural que visa a patrimonialização do território sudoeste do Mato grosso do Sul e que atinge grande parte da linha de fronteira desse estado brasileiro. Ademais, buscou caracterizar questões sociais e econômicas regionais que salientam a necessidade de atuar para criar mecanismos de desenvolvimento do território em virtude de sua clara depressão socioeconômica. Desenvolver ações de desenvolvimento para as comunidades indígenas locais se faz prioritário, tendo em conta os elevados riscos socioeconômico de essas comunidades que indiquem negativamente em toda o território.

23. $\mathrm{IUSD}=4,057 \mathrm{BRL}$, cambio em 23 de Agosto de 2019 
A partir de análises documentais, principalmente cartográficas da região, observase a possibilidade de criação de um autêntico itinerário cultural, com características históricas únicas e localizado em uma extensa faixa territorial. Um trabalho que recupera parte importante da memória histórica do estado e possibilita a criação de um elemento que pode impactar de forma positiva a sociedade permitindo incorporar valores histórico culturais que permitam criar elementos para elevar os parâmetros econômicos, sociais e educativos de uma região depressiva e vulnerável, como indicado na análise socioeconômica, onde os indicadores como rendimento médio dos ocupados, vulnerabilidade à pobreza, renda, IDHM, entre outros, não são nada animadores. 


\section{REFERÊNCIAS}

AICS (20I6). Guía metodológica para la elaboración de itinerarios culturales. Programa de Asistencia Técnica al Ministerio de Culturas y Turismo - Il Fase - Editado por Renzo Carlucci y Simona Piras en el marco del Programa de Asistencia Técnica al Ministerio del Culturas y Turismo de Bolivia, financiado e implementado por la AICS - Agenzialtaliana per la CooperazionealloSviluppo. Agencia Italiana de Cooperación al Desarrollo. 2016. Catálogo [em linha]: <http://tucuna.info/images/manuales/ro-GuiaMetodologicaltine rariosCulturales-27.06.I7.pdf $>$ [Consulta: 23 de Agosto de 20I9].

Archivo General de Indias (Sevilla, España) Consejo de Indias (España) «Mapa de América del Sur desde el Ecuador hasta el Estrecho de Magallanes». Código de Referencia: ES.4Io9I.AGI/27.3//MP-BUENOS_AIRES,4. Catálogo [em linha] <http://pares.mcu.es/ ParesBusquedas20/catalogo/description/I6777> [Consulta: 23 de Agosto de 2019].

BNDigital. «Croquis da parte da Província de Matto Grosso imediata aos limites com a República do Paraguay projectada para melhor intelligência de uma exposição que o acompanha». I876. I mapa ms, col, 48,5 x 85cm em folha de 52 x 89. Catálogo [em linha]: de la biblioteca. <http://objdigital.bn.br/objdigital2/acervo_digital/div_cartografia/cart24989o/ cart24989o.html>. [Consulta: 23 de Agosto de 2019].

BVPB. Detalhe do «Plano del Virreinato de Buenos aires en el qual se halla remarcada la linea divisoria y los marcos que en ella se pusieron desde Castillos en la Costa del mar hta la bsoca del Jaury por la za za y 4 a Partida de la demarcacn de I759 / yandebio ser trazado este mapa con areglo a los elementos y noticias que adquirieron en aquel entonces estos demarcadores y las partes por donde hizieron sus viajes como el Parana, Paraguay, Igatimiseran particularmente designadas con bastante esxactitudhaviendo estado empleado el dho Custodiado por parte de Portugal en la expresada demarcación ; copiado en I80I para Hidrográfico de Madrid» Biblioteca Virtual del Patrimonio Bibliográfico. Catálogo [em linha]: de la biblioteca. <http:// bvpb.mcu.es/es/consulta/registro.cmd?id=4346I2> [Consulta: 23 de Agosto de 20I9].

Busón, C. \& Zamberlan, C. (2018). Rescate de caminos históricos como pauta de desarrollo sostenible: el camino para los yerbales, una ruta cultural de integración binacional. Revista desenvolvimento, fronteiras e cidadania - v.2, n.I, p. II-I6, abril de 2018 Catálogo [em linha] <https://periodicosonline.uems.br/index.php/fronteiracidadania/ article/view/2625/2092> [Consulta: or de setembro de 2019].

Martorell Carreño, A. (20Io). Itinerarios culturales y patrimonio mundial: Lima. Editora Universidad de San Martín de Porres: Fondo Editorial, 742 p.

De ANgelis, P. (I836). Colección de obras y documentos relativos a la historia antigua y moderna de las provincias del Rio de la Plata, ilustrados con notas y disertaciones. Tomo IV: Buenos Aires. Imprenta del Estado, 7I8 p.

DíAz de Guzmán, R. (I835). Historia Argentina del descubrimiento, población y conquista de las provincias del Río de la Plata / escrita por Ruy Díaz de Guzmán, en el año de I6ı2. Tomo Primero, Buenos Aires, Imprenta del Estado. Catálogo [em linha]: de la biblioteca. <http://www.cervantesvirtual.com/nd/ark:/5985I/bmc9c6w2> [Consulta: 24 de Agosto de 2019]

Fischer, T. (20I2). Gestão social do desenvolvimento de territórios. Rev. Psicol., Organ. Trab. [online]. , vol.ı2, n.I pp. II3-II9. catalogo [em linha]: <http://pepsic.bvsalud.org/scielo. php?script=sci_arttext\&pid=SI984-665720I2000 Iooo Io\&lng=pt\&nrm=iso $>$. [Consulta: 24 de Agosto de 20I9], ISSN i984-6657. 
GADELHA, R. (2013). IHS: Jesuítas portugueses no Paraná: uma contribuição para a história da expansão territorial do Brasil. IHS: Antiguos Jesuitas en Iberoamérica ISSN-e 23I4-3908, Vol. I, No ${ }^{\circ}$. I. (Ejemplar dedicado a: (Enero / Junio)), págs. 4-23.

Holanda, S. B. (20IO). Visão do Paraíso : os motivos edênicos no descobrimento e colonização do Brasil : São Paulo : Companhia das Letras, 453 p.

Holanda, S. B. (2016). Raízes do Brasil: Editora Companhia das Letras, 544 p.

IBGE. (20I0). Censo catalogo [em linha]: $<$ https://censozoro.ibge.gov.br/> [Consulta: 23 de Agosto de 2019].

ICOMOS (2008). Carta Dos Itinerários Culturais. Elaborada pelo Comité Científico Internacional dos Itinerários Culturais (ClIC) do ICOMOS, ratificada pela $\mathrm{I}^{\mathrm{a}}{ }^{\mathrm{A}}$ Assembleia Geral do ICOMOS, em 4 de Outubro de 2008, no Québec, Canadá, [emlinha]<http://icomos. fa.utl.pt/documentos/cartasdoutrina/lCOMOSPortugalCartaltinerariosCulturais.doc> [Consulta: 23 de Agosto de 2019].

IPHAN (2009). Anteproyecto de itinerarios culturales del Mercosur. Salvador, Bahia, Brasil, nos dias 23 e 24 de janeiro de 2009. Realizada sob os auspícios do Instituto de Patrimônio Histórico e Artístico Nacional. 2009 catalogo [em linha]: <http://portal.iphan.gov.br/ uploads/ckfinder/arquivos/Anteprojeto_itinerarios_culturais_mercosul_portugues.pdf> [Consulta: 23 de Agosto del 20I9].

LAmAs, A. (1873-1875). Historia de la conquista del Paraguay, Río de la Plata y Tucumán: Editor: Casa Editora «Imprenta Popular», páginas: 5 v. (CXLVIII, $468 ; 396 ; 570 ; 489 ; 364$ p.).

MARTín-Merás, L. (2007). «Fondos cartográficos y documentales de la Comisión de Límites de Brasil en el siglo XVIII en el Museo Naval de Madrid», Terra Brasilis [Online], 7 - 8 9 | 2007, posto online no dia 05 novembro 2012, <http://journals.openedition.org/ terrabrasilis/402> [Consulta: 23 de Agosto de 2019].

SiLVA, E. P. (2000) Património e identidade: os desafios do turismo cultural. Antropologicas. n.4, p 217-224, Porto, Portugal.

Tесно, N. (I897). Historia de la provincia del Paraguay de la Compañía de Jesús por el P. Nicolás del Techo (I6II-I685) ; versión del texto latino por Manuel Serrano y Sanz ; con un prólogo de Blas Garay. Madrid Librería y Casa Editorial A. de Uribe y Compañía. 5 Volumes. Catálogo [em linha]: de la biblioteca. <http://bdh.bne.es/bnesearch/detalle/ bdhoooor40430> [Consulta: 23 de Agosto de 2019].

UNESCO (2009). $2^{\circ}$ Relatório Mundial da UNESCO: Investir na diversidade e no diálogo intercultural. Organização das Nações Unidas para a Educação, a Ciência e a Cultura 7 place de Fontenoy 75007 Paris, France, 2009 Catálogo [em linha]: de la biblioteca. <https:// unesdoc.unesco.org/ark:/48223/pfoooor84755_por> [Consulta: 23 de Agosto de 2019]. 


\section{Presentación · Foreword}

\section{Artículos · Articles}

17 THOMAS BRASDEFER

Making space for freedom: The situationist Guide to protesting · Crear espacio

35 Carlos B. Buson; Carlos O. Zamberlan; Cláudia M. ${ }^{a}$ Sonaglio \& FABrícIo J. Missio

A proposta do caminho para os ervais: desenvolvendo territórios através da criação de itinerários culturais na fronteira Brasil-Paraguai . The Proposal of «Caminho para os Ervais»: Developing Territories through Creation of Cultural Itineraries in Brazil-Paraguay Border

55

Julia J. Carrero Espinosa y Pablo Martínez de Anguita

Hacia una ética del paisajismo

21 Concepción Fidalgo Hijano, Juan Antonio González Martín; Mario Corral Ribera; Rosario García Giménez \& Carlos Arteaga Cardineau Peatlands Evolution in Central Iberia (Montes de Toledo, Spain) and its Link to Anthropogenic Processes: A Cartography-Based Study . Evolución de las turberas en el centro de la Península Ibérica (Montes de Toledo) y su relación con los procesos

\section{Carlos Guallart Moreno}

La cartografía digital generada por la COVID-19: Análisis y tipologías . The

35 JuAn Guerra Guerra

Turismo de paisaje, desarrollo sostenible y ordenación del territorio en la isla de La Palma (Islas Canarias)

Territorial Planning in La Palma (Canary Islands)

\section{David LaCÁmara AYlón}

La ruptura de un equilibrio. El siglo XV y la paulatina ocupación y degradación de los espacios naturales zaragozanos

\section{and the Progressive Occupation and Degradation of the Natural Spaces in Zaragoza}

191 Milagros Mayoral Peñas; Beatriz Cristina Jiménez Blasco; Silvana Sassano luiz \& Rosa Resino García

Inmigración y educación: desigualdades y experiencias de discriminación en la Comunidad de Madrid

of Discrimination at Madrid's Community

\section{Mercedes MilLán Escriche}

La planificación como impulsora de la evolución socioeconómica y el desarrollo local de Torre Pacheco (Murcia)

\section{Evolution and Local Development of Torre Pacheco (Murcia)}

\section{7 Álvaro-Francisco Morote Seguido}

¿Cómo se trata el tiempo atmosférico y el clima en la Educación Primaria? Una exploración a partir de los recursos y actividades de los manuales escolares de Ciencias Sociales - How Weather and Climate is Treated in Primary Education? An Exploration from the Resources and Activities of Social Sciences Textbook

\section{José Ramón Sánchez Holgado \\ La aproximación a los restos arqueológicos de la batería de Varadero mediante el análisis de la cartografía. The Approach to the Archaeological Remains of the Varadero Battery through the Analysis of the Cartography}

\section{Reseñas · Book Review}

305 Hadjichambis, Andreas Ch.; Reis, Pedro; ParaskeVa-Hadjichambi, Demetra; ČınČERA, Jan; Boeve-de PAuw, Jelle; GerıCKE, Niklas; KNIPPELs, Marie-Christine (Eds.) (2020). Conceptualizing Environmental Citizenship for $21^{\text {st }}$ Century Education, Springer Open, 264 pág. ISBN: 978-3-030-20248-4 (JOSÉ JESúS DELGADO-PEÑA)

314

Martínez de Pisón, Eduardo (2019). Geografías y paisajes de Tintín. Viajes, lugares y dibujos, Madrid: Fórcola Ediciones, 187 pp. ISBN: 978-84-17425-36-4

315 men Murga-Menoyo, M. ${ }^{a}$ A. y Bautista-Cerro, M. ${ }^{a}$ J. (Editoras) (2019). Guía PRADO. Sostenibilizar el currículo de la Educación Secundaria. Madrid: UNED. 422 págs. Editorial. 162 pp. ISBN- $978-84-9080-762-8$

327 Reques Velasco, Pedro y Afonso, Luiekakio (2017). África como reto demográfico. Angola como paradigma. (Africa as a demographic challenge. Angola as a paradigm). Madrid: Casa África y Libros de la Catarata, 112 pp. ISBN: 97884-9097-278-6

\section{Imágenes y palabras • Pictures and Words}

333 Carlos J. Pardo Abad

Etiopía: recorrido por algunos paisajes naturales y culturales

\section{Síntesis de Tesis Doctorales · Summaries of Doctoral Thesis}

\section{José Antonio GonzÁlez DíAz}

Modelos de gestión del territorio, paisaje y biodiversidad en un espacio de montaña: la Reserva de la Biosfera de Redes, Departamento de Geografía de la Universidad de Oviedo. Directores/as: Dra. Rocío Rosa García \& Dr. Felipe Fernández García. Fecha de lectura: Julio 2019

\section{Alejandro Vallina Rodríguez}

Aspectos Naturales y culturales del paisaje de la Sierra de Guadarrama desde el análisis de su calidad visual. Departamento de Geografía. Universidad Autónoma de Madrid. Directora: Dra. Concepción Camarero Bullón. Fecha: 10 de julio de 2020

Historia de la Geografía española · History of Geography in Spain

36 Eva M. ${ }^{a}$ Martín-Roda Geografía y docencia en el legado del profesor José Estébanez Álvarez 